\title{
A spectroscopic investigation of the weathering of a heritage Sydney sandstone
}

K.H. Ip, B.H. Stuart*, A.S. Ray and P.S. Thomas

Department of Chemistry, Materials and Forensic Sciences, University of Technology, Sydney, PO Box 123, Broadway NSW 2007, Australia

* Corresponding author

Email: Barbara.Stuart@uts.edu.au

Phone: +61295141790

Fax: +61295141460

\begin{abstract}
Infrared spectroscopy has been employed in a study of the degradation of heritage Sydney sandstone used in St Mary’s Cathedral in Sydney, Australia. Spectra were used to characterise the clay components taken from weathered and unweathered sandstone blocks removed from the Cathedral as part of a restoration programme. Two types of kaolin clays kaolinite and its polymorph, dickite - have been identified. A higher amount of dickite present in the clay of weathered sandstone indicated that a kaolinite-to-dickite transformation occurs upon weathering. X-ray photoelectron spectroscopy was also used to confirm the presence of a more thermally stable polymorph of the kaolinite in the sandstone.
\end{abstract}

Keywords: infrared spectroscopy; sandstone; clay; weathering; x-ray photoelectron spectroscopy 


\section{Introduction}

A number of heritage buildings located in Sydney, Australia, are built from locally quarried sandstone and contribute a unique character to the city. After a period of exposure to the elements, sandstone buildings in Sydney are showing signs of deterioration. The majority of heritage sandstone buildings exhibit a golden brown colour upon weathering of the "yellow block" sandstone and the appearance of such colour is a result of the oxidation of iron rich minerals in the stone [1]. Although Sydney sandstones retain detailed carving and the integrity of the stone structure on weathering, they are relatively brittle compared to the less weathered part of the stone core and can be shattered by the application of a minor force. In order to determine the appropriate conservation techniques for such buildings, it is important to gain a thorough understanding of the method of degradation of the building stones.

Sydney yellow block sandstones typically contain relatively large amounts of sand (60-68\%) bound together by a 16-25\% clay-based matrix, with small quantities of impurities including iron-rich minerals [1]. The focus of this study is the cementing clay component of the stone as the clay is critical to the integrity of the material. Infrared spectroscopy and Xray photoelectron spectroscopy (XPS) have been used to compare the clays isolated from weathered and unweathered sandstones obtained from St Mary’s Cathedral in Sydney. Sandstone removed from the cathedral was part of a restoration programme by the Heritage Group of the New South Wales Department of Planning. In addition, clays samples with nonstructural iron removed were also investigated in order to determine the significance of the impurities in the analyses. 


\section{Materials and methods}

\section{Materials}

Sandstone samples from St Mary’s Cathedral were supplied by Gosford Quarries Pty Ltd (Australia). The samples obtained were the more extensively decayed yellow block sandstones replaced in recent years as part of restoration programmes in Sydney. The weathered surfaces were separated from the unweathered cores of the decayed stones by use of a diamond saw and small amounts of water were employed as a coolant during cutting.

The clay-based material was separated from the sandstone samples. Both weathered and unweathered sandstones were manually crushed using a mortar and pestle and then mixed with distilled water $\left(5 \mathrm{gL}^{-1}\right)$. An ultrasonic probe with frequency of $20 \mathrm{kHz}$ and energy of $20 \mathrm{~W}$ was used to dislodge the clay-based material from the sand particles [2,3]. The decanted clay materials were suspended in distilled water and particles $\leq 2 \mu$ m were collected using a gravity settling method according to Stokes’ Law [4,5]. The clay collected by centrifugation was dried in a $50^{\circ} \mathrm{C}$ oven overnight and separated into two portions. One portion was stored in a desiccator until analysis and the second portion was further treated with $\mathrm{Na}_{2} \mathrm{~S}_{2} \mathrm{O}_{3} \cdot 5 \mathrm{H}_{2} \mathrm{O}$ and $\mathrm{NaHCO}_{3}$ to remove non-structural iron (iron impurities) from the clay samples [6]. Clay samples were treated with the same process three times. The washed solutions were combined and inductively coupled plasma - atomic emission spectroscopy (ICP-AES) was used for the elemental analysis of both weathered and unweathered samples to ensure total removal of non-structural iron. Standard ordered kaolinite from the KentuckyTennessee Clay Company (USA) was used for comparison purposes. 


\section{FTIR spectroscopy}

Mid-infrared spectra were recorded using a Nicolet DRIFT sampling accessory in a Nicolet Magna-IR 760 Fourier transform infrared (FTIR) spectrometer. For each sample, 6 mg of powdered sample was finely ground with $40 \mathrm{mg}$ of $\mathrm{KBr}$ powder using an agate mortar and pestle. Background spectra were recorded using ground powdered $\mathrm{KBr}$. A resolution of 4 $\mathrm{cm}^{-1}$ was used and 256 scans were collected for each sample.

\section{$X$-ray photoelectron spectroscopy}

A Vacuum Generators XPS system (Sussex, England) with a monochromatic AlK $\alpha$ Xray source was used to produce the XPS spectra of the clay samples. The clay powder was sprinkled onto double-sided tape and secured onto the sample holder of the instrument [7]. The XPS system was operated with a $10 \mathrm{kV}$ current and the pressure in the analyser chamber was $1.33 \times 10^{-6} \mathrm{~Pa}$. Low resolution scans were collected at an energy of $50 \mathrm{eV}$ with step size of $1 \mathrm{eV}$ every $0.5 \mathrm{~s}$, while high resolution scan was obtained at an energy of $20 \mathrm{eV}$ with a step size of $0.5 \mathrm{eV}$ every $6 \mathrm{~s}$.

\section{Results and discussion}

\section{FTIR spectroscopy}

The FTIR spectra obtained for both weathered and unweathered clay samples, as well as a spectrum of standard kaolinite, before non-structural iron removal were obtained. The spectrum of the O-H stretching region of the standard kaolinite shows a distinctive pattern of well crystallised kaolinite clay (Figure 1). Four relatively sharp O-H stretching bands are detected, with the band at $3621 \mathrm{~cm}^{-1}$ arising from the intralattice hydroxyl groups (O-H groups between tetrahedral and octahedral sheets) in the kaolinite structure [8]. The band at 
$3697 \mathrm{~cm}^{-1}$ is associated with the stretching vibration of the interlayer hydroxyl groups $(\mathrm{O}-\mathrm{H}$ groups between aluminosilicate layers) and the doublet between these two bands, with components at 3669 and $3654 \mathrm{~cm}^{-1}$, is due to the out-of-plane stretching vibrations [9]. By comparison, both the spectra of the weathered and unweathered clay samples before iron removal show a triplet of peaks at 3710, 3656 and $3621 \mathrm{~cm}^{-1}$ instead of the four peaks observed in the standard kaolinite. The band at $3621 \mathrm{~cm}^{-1}$ remains at the same position, while the peak arising from the stretching vibration of the basal plane hydroxyl groups shifts from $3697 \mathrm{~cm}^{-1}$ for the standard kaolinite to $3710 \mathrm{~cm}^{-1}$ for the cementing clay. In addition, the intensity and sharpness of this peak for the cementing clay samples has changed compared to the same peak for kaolinite: lower intensity and broadened peaks are observed in both weathered and unweathered clay samples in comparison with peaks for standard kaolinite. The doublet representing the basal plane hydroxyl groups at 3669 and $3654 \mathrm{~cm}^{-1}$ has been replaced by one single peak at $3656 \mathrm{~cm}^{-1}$ in both the weathered and unweathered cementing clays. The replacement of the doublet by a single peak suggests that the cementing clay is a typical disordered kaolinite with some stacking patterns of its more crystallised polymorphs, dickite and nacrite, in its structure [9-11]. The shift of the peak representing the interlayer O$\mathrm{H}$ groups at 3697 to $3710 \mathrm{~cm}^{-1}$ in the cementing clays further confirms the structural deviation of the cementing clays compared to that of the standard kaolinite. The lower intensity and broadened profile of this peak in both weathered and unweathered cementing clays indicates the reduced crystallinity of the cementing clay compared to that of the standard kaolinite. The reduced crystallinity of the cementing clay may result in the weakening of the interlayer attraction making it more susceptible to degradation.

Variations were also observed between the spectra for cementing clay samples prior to iron removal and for the standard kaolinite in the fingerprint region (Figure 2). A doublet observed in the standard kaolinite with peaks at 1116 and $1105 \mathrm{~cm}^{-1}$ merge to form one peak 
in the weathered and unweathered clay samples at $1120 \mathrm{~cm}^{-1}$. The singlet indicates a difference in particle sizes or shapes in the samples clays [12,13]. A peak near $1100 \mathrm{~cm}^{-1}$ arises from the asymmetric Si-O-Si stretching vibration [14] and the particle size is believed to be directly proportional to the intensity of this peak [15].

A comparison of the bands at 941 and $916 \mathrm{~cm}^{-1}$ in the kaolinite and cementing clays spectra also shown differences (Figure 2). The intensity of the band at $916 \mathrm{~cm}^{-1}$ is higher than that of the band at $941 \mathrm{~cm}^{-1}$ in the spectrum of the standard kaolinite, while the intensities of the bands are similar in both the spectra of the weathered and unweathered cementing clay samples. The bands at 941 and $916 \mathrm{~cm}^{-1}$ are believed to arise from the Si-O stretching and AlO-H librations, respectively [16-18]. The observed deviation of the peaks at 941 and $916 \mathrm{~cm}^{-1}$ suggests a slight difference in the crystal structure of the cementing clay in the sandstones compared to that of the standard kaolinite.

Small changes are also observed to two weak bands at 798 and $759 \mathrm{~cm}^{-1}$. Both bands show equal intensity in standard kaolinite, while the band at $798 \mathrm{~cm}^{-1}$ in both cementing clays shows a higher intensity than that at $759 \mathrm{~cm}^{-1}$. The pattern of the two bands at 798 and 759 $\mathrm{cm}^{-1}$ observed in the cementing clay spectra appears similar to that of the dickite clay. The more intense peak at $798 \mathrm{~cm}^{-1}$ in the spectrum of the cementing clay provides evidence that the more ordered polymorph, dickite, is present [19]. The finding of dickite in the cementing clays may be due to a kaolinite-to-dickite transition as a result of structural changes in the kaolinite in the sandstone [20]. This transformation could be due to the depth of the original sandstone when quarried [21,22], temperature variation [23] and/or the porosity of the sandstone as high porosity and permeability allows for the precipitation of dickite from kaolinite and K-feldspar [24,25].

Weak shoulders at 3605 and $882 \mathrm{~cm}^{-1}$ are observed in the spectra of the clay. These arise from the $\mathrm{O}-\mathrm{H}$ stretching and bending vibrations of $\mathrm{AlFe}^{3+} \mathrm{OH}$ where $\mathrm{Fe}^{3+}$ is substituted 
$\mathrm{Al}^{3+}$ in the octahedral sites of the aluminosilicate structures [26]. This substitution is believed to be responsible for the recrystallisation of the second generation clay which retains the original aluminosilicate crystal structure. The newly recrystallised clay has a more ordered crystal structure with similar characteristics to dickite from the kaolin group. Although the substitution will ultimately destabilise the crystal structure of the cementing clay, it retains the 1:1 octahedral/tetrahedral aluminosilicate frame work at the initial stage of the degradation mechanism. In addition, $\mathrm{Fe}^{3+}$, together with a mono valence cation, such as $\mathrm{K}^{+}$, is also believed to be substituting for $\mathrm{Si}^{4+}$ in the tetrahedral site [27].

Although the features of the spectra obtained for the unweathered and weathered clay components are very similar, differences are noted in the relative intensities of the bands in these spectra. The intensities of the $\mathrm{O}-\mathrm{H}$ stretching bands relative to the bands observed in the fingerprint region for the weathered sample are lower than the relative intensities observed for unweathered clay and standard kaolinite spectra. Additionally, within the O-H stretching region, the relative intensity ratio of the intra-layer $\mathrm{O}-\mathrm{H}$ stretching band at $3656 \mathrm{~cm}^{-1}$ and the $3621 \mathrm{~cm}^{-1}$ band is lower for the weathered clay compared to the ratio observed in the spectrum for the unweathered clay (Figure 1). The changes to the $\mathrm{O}-\mathrm{H}$ bonds indicate that the hydrogen bonding in alumino-silicate layer of the clay is affected by weathering, contributing to the disruption of the clay structure.

The spectra of the weathered and unweathered cementing clay and the standard kaolinite after non-structural iron removal show similar patterns to the spectra of the clays prior to the treatment of iron removal. Both weathered and unweathered cementing clays show the triplet in the $\mathrm{O}-\mathrm{H}$ stretching region. The band at $3621 \mathrm{~cm}^{-1}$ remains unchanged, the two bands at 3656 and $3710 \mathrm{~cm}^{-1}$ are broadened furthered upon non-structural iron removal. In addition, these two bands appear to be more broadened in the weathered clay samples 
compared to the unweathered clays. The fingerprint regions of the clays after iron removal show the same features as the spectra before iron removal.

\section{XPS spectroscopy}

The low resolution XPS spectra of the weathered and unweathered clay samples before non-structural iron removal indicate the presence of aluminium, silicon, carbon and oxygen (Figure 3) $[28,29]$. These elements arise from the aluminosilicate structure and other minerals in the cementing materials in the sandstones, such as carbonates and metal oxides. A binding energy near $700 \mathrm{eV}$ is observed only in the weathered clay samples, suggesting the presence of a small amount of iron in the cementing clay structure. In order to obtain better resolution of the iron peaks, a high resolution scanning was performed from 700-740 eV. The high resolution XPS spectra of all the weathered clay samples show typical patterns of iron bonds in its two spin-orbits around $700 \mathrm{eV}$ (Figure 4). The spectra of the treated clays are noisy due to the low iron concentration and the relatively high detection limit of the instrument; nonetheless, the presence of iron in the weathered clay samples is evident.

The results confirm that iron exists as both structural and non-structural iron in the clay samples, although it appears to be mostly non-structural iron. The high resolution XPS spectra reveal the presence of iron in the aluminosilicate structure which cannot be removed through treatment. This result agrees with findings by several other researchers [30-32]. Although iron was not detected in the unweathered clay samples using this method (with a detection limit of 6 ppm), it has been detected in lower concentrations using ICP - AES. Although there is no indication as to whether the iron peaks detected are that of $\mathrm{Fe}^{3+}$ or $\mathrm{Fe}^{2+}$, a similar XPS pattern has been observed in the analysis of $\mathrm{Fe}^{3+}$ in nontronite, a 2:1 dioctahedral smectite clay mineral with $\mathrm{Fe}^{3+}$ as the predominant octahedral cation [33]. Since $\mathrm{Fe}^{3+}$ has the same charge as $\mathrm{Al}^{3+}$ in the aluminosilicate structure, isomorphous substitution 
readily occurs when the source of iron is abundant. Sandstones are natural materials which contain several iron rich minerals. With $\mathrm{FeCO}_{3}$ (siderite), $\mathrm{FeS}_{2}$ (pyrite) and amorphous goethite $[\alpha-\mathrm{FeO}(\mathrm{OH})]$, together with a trace amount of iron in groundwater, a sufficient amount of iron is available for substitution to take place. The iron in these compounds exists in the ferrous $\left(\mathrm{Fe}^{2+}\right)$ state due to the low concentration of dissolved oxygen, once the stones are quarried and exposed to air, the ferrous iron is oxidised to the ferric $\left(\mathrm{Fe}^{3+}\right)$ state [1]. Although the substitution of $\mathrm{Al}^{3+}$ in the octahedral sites by $\mathrm{Fe}^{3+}$ is a common phenomenon in the crystal structures of clay minerals, other types of substitution, such as the substitution of $\mathrm{Si}^{4+}$ by $\mathrm{Fe}^{3+}$ and $\mathrm{K}^{+}$, is also possible [31,34-36]. This finding supports the FTIR results, where $\mathrm{AlFe}^{3+} \mathrm{OH}$ was detected in the cementing clay structure.

These findings are in agreement with the results of a study of the St Mary’s Cathedral sandstone using thermal analysis and X-ray diffraction [37]. TGA and DSC analysis of clays extracted from weathered and unweathered sandstone demonstrated that a polymorphic clay structure such as that of dickite was found in the clay material, resulting in an extra peak in the dehydroxylation region. XRD hot stage results supported the proposal of the presence of a more ordered clay structure in the cementing material.

\section{Conclusions}

A deviation from the crystal structure of standard kaolinite to its more ordered polymorph, dickite for sandstones was demonstrated by FTIR spectroscopy. Hydrogen bonding in the interlayer regions of the aluminosilicate layers from the cementing clay decreases upon weathering, contributing to the weakening of the clay structure. Cation substitution by $\mathrm{Fe}^{3+}$ for $\mathrm{Al}^{3+}$ in the octahedral sites of the clay layers is observed in iron rich sandstone such as Sydney sandstone. Although substitutions of these types destabilise the crystal structures of the cementing clay, the phenomenon ensures the retention of the integrity 
of the overall aluminosilicate structure. The XPS results imply that a large amount of iron is present in the weathered sandstone samples. Iron peaks are still observed upon non-structural iron removal. This further supports the observation of isomorphous substitution of $\mathrm{Al}^{3+}$ by $\mathrm{Fe}^{3+}$

\section{Acknowledgements}

The authors wish to acknowledge the support of the Heritage Group, NSW Department of Planning and Gosford Quarries Pty Ltd.

\section{References}

1. G.H. McNally, B.J. Franklin, Sandstone City - Sydney’s Dimension Stone and Other Sandstone Geomaterials, Geological Society of Australia, Sydney, 2000.

2. R. Roscoe, P. Buurman, E.J. Velthorst, Eur. J. Soil Sci. 51 (2000) 445 - 454.

3. M.W. Schmidt, C. Rumpel, I. Kogel-Knabner, Eur. J. Soil Sci. 50 (1999) 87 - 94.

4. D. Carroll, Clay Minerals: A Guide to Their X-ray Identification, Geological Society of America, Colorado, 1970.

5. E.M. Rutledge, L.P. Wilding, M. Elfield, Proc. Soil Sci. Soc. Amer. 31 (1967) 287 - 288.

6. O.P. Mehra, M.L. Jackson, Clay Miner. 7 (1960) 317 - 327.

7. K.E. Nissen, M.G. Stevens, B.H. Stuart, A.T. Baker, J. Polym. Sci. Polym. Phys. 39 (2001) $623-633$.

8. R.E. Grim, Clay Mineralogy, second ed., McGraw-Hill, New York, 1968.

9. J. Madejova, Vib. Spectrosc. 31 (2003) $1-10$.

10. R. Prost, A. Dameme, E. Huard, J. Driard, L.P. Leydecker, Clay Miner. 37 (1989) 464 468.

11. V.C. Farmer, J.D. Russell, Spectrochim. Acta 20 (1964) 1149 - 1173. 
12. V.C. Farmer, J.D. Russell, Spectrochim. Acta 22 (1966) 389 - 398.

13. J.L. Rendon , C.J. Serna, Clay Miner. 16 (1981) 375 - 381.

14. X. Chatzistavrou, T. Zorba, K. Chrissafis, G. Daimakamis, E. Kontonasaki, P. Koidis, K.M. Paraskevopoulos, J. Therm. Anal. Cal. 85 (2006) 253 - 259.

15. J. Osswald, K.T. Fehr, J. Mat. Sci. 41 (2006) 1335 - 1339.

16. N.N. Zinchuk, D.D. Kotel’nikov, A.I. Gorshkov, Lith. Min. Res. 38 (2003) 87 - 96.

17. F. Kooli, J. Mat. Chem. 12 (2002) 1374 - 1380.

18. J.T. Kloprogge, S. Komarneni, K.Yanagisawa, R.L. Frost, R. Fry, J. Mat. Sci. Lett. 17 (1998) $1853-1855$.

19. M.J. Wilson, Clay Mineralogy: Spectroscopic and Chemical Determinative Methods, Chapman and Hall, London, 1994.

20. B. Lanson, D. Beaufort, G. Berger, A. Bauer, A. Cassagnabere, A. Meunier, Clay Miner. $37(2002) 1-22$.

21. B. Lanson, D. Beaufort, G. Berger, S. Petit, J.C. Lacharpagne, Bull. Cent. Rech. Explor. Prod. Elf-Aquitane 19 (1995) 243 - 265.

22. D. Beaufort, A. Cassagnabere, S. Petit, B. Lanson, G. Berger, J.C. Lacharpagne, H. Johansen, Clay Miner. 33 (1998) 297 - 316.

23. A. Cassagnabere, I.K. Iden, H. Johansen, J.C. Lacharpagne, D. Beaufort, in: H. Kodama, A.R. Mermut, J.K. Torrance (Eds.), Clays for Our Future: Proceedings of the 11th International Clay Conference, Mineralogical Association of Canada, Ottawa, 1999, pp 97102.

24. J. Ferrero, B. Kubler, Bulletin du Service de la Carte Géologique d’Alsace et Lorraine 17 (1964) $247-261$.

25. W. Zimmerle, H. Rosch, Zentralblatt fur Geologie und Palaontologie 1 (1991) 1175 1196. 
26. E. Mendelovici, S. Yariv, R. Villalba, Clay Miner. 14 (1979) 323 - 331.

27. K.H. Friolo, B.H. Stuart B, A.S. Ray, J. Cult. Her. 4 (2003) 211 - 220.

28. D. Briggs, M.P. Sean, Practical Surface Analysis Vol. 1: Auger and X-ray Photoelectron Spectroscopy, second ed., Wiley, New York, 1990.

29. B.Crist, Handbook of Monochromatic XPS Spectra, Wiley, Chichester, 2000.

30. A.J. Herbillon, M.M. Mestdagh, L. Vielvoye, E.G. Derouane, Clay Miner. 11 (1976) 201220.

31. B.R. Angel, W.E.J. Vincent, Clay Miner. 26 (1978) 263-272.

32. K. Bahranowski, E.M. Serwicka, L. Stoch, P. Strycharski, Clay Miner. 28 (1993) 379391.

33. J.W. Stucki, C.B. Roth, W.E. Baitinger, Clays and Clay Miner. 24 (1976) 289 - 292.

34. P.L. Hall, Clay Miner. 15 (1980) 321-335.

35. M.M. Mestdagh, L. Vielvoye, A.J. Herbillon, Clay Miner. 15 (1980) 1-13.

36. S. Petit, A. Decarreau, Clay Miner. 25 (1990) 181-196.

37. K.H. Ip, B.H. Stuart, P.S. Thomas and A.S. Ray, J. Therm. Anal. Cal., in press. 